\title{
New substitutions of mitochondrial DNA in Iranian autistic children
}

Mansoureh Akouchekian ${ }^{1}$, Mitra Hakim Shooshtari², Hamed Heidary ${ }^{3}$, Parisa Moeinian ${ }^{4}$

\author{
${ }^{1}$ Cellular and Molecular Research Center, Iran University of Medical Sciences, Tehran, \\ Iran \\ ${ }^{2}$ Mental Health Research Center, Tehran Institute of Psychiatry - School of Medicine, \\ Iran University of Medical Sciences, Tehran, Iran \\ ${ }^{3}$ Human Genetics Department, Ali Asghar Hospital, Iran University of Medical \\ Sciences, Tehran, Iran \\ ${ }^{4}$ Department of Medical Genetics and Molecular Biology, School of Medicine, Iran \\ University of Medical Sciences, Tehran, Iran
}

Submitted: 22 April 2018

Accepted: 1 July 2018

Arch Med Sci Civil Dis 2018; 3: e87-e91

DOI: https://doi.org/10.5114/amscd.2018.78769

Copyright $\odot 2018$ Termedia \& Banach

\begin{abstract}
Introduction: Autism spectrum disorders (ASDs) are neurodevelopmentally complex diseases with causative de-novo and inherited genetic factors. They contain a range of cognitive and behavioral conditions such as Asperger's syndrome, pervasive developmental disorder and autism. Our study subjects were children with autistic behaviors (15-60 CARS Score).

Material and methods: The DNA extraction process was done using a GeNet Bio DNA extraction kit, and the region of interest was amplified using independent PCR runs. After purification of PCR products, both strands were sequenced by the Big Dye Termination system. The automated sequencing on an $A B I 3700$ was directly determined with a capillary sequencer machine. Both primers' sequencing results were analyzed using a bioinformatics tool, Sequencher Software 5.

Results: In the population we studied, the variant G9055A (located at ATP6) was reported to be pathogenic (CAAD > 20 and PolyPhen shows it to be probably damaging). In this variant amino acid alanine converts to threonine. A to T substitutions induce accumulation of amyloid fibril in the brain because threonine prefers to form a $\beta$ sheet as a necessary stage in the amyloidogenic process.

Conclusions: In our study of patients with autism, we found one case having an interesting association with amyloidosis. It is hoped that by finding such markers, the children will be treated with more certainty.
\end{abstract}

Key words: mtDNA, ATPase 6/8, amyloidogenic processes.

\section{Introduction}

Autism spectrum disorders (ASDs) are neurodevelopmentally complex diseases with causative de-novo and inherited genetic factors. They include a range of cognitive and behavioral conditions such as Asperger's syndrome, pervasive developmental disorder and autism. The etiology of autism is unclear but it is known that it arises in early childhood. The disease symptoms include impaired reciprocal social interactions, isolated interests, epilepsy, motor defects, gastrointestinal abnormalities, aggression, hyperactivity and sleep and mood disorders [1-4]. Among these, ste-

\author{
Corresponding author: \\ Mansoureh Akouchekian \\ Cellular and Molecular \\ Research Center \\ Iran University of \\ Medical Sciences \\ Crossroads of Hemmat \\ and Chamran Expressways \\ 1449614535 Tehran, Iran \\ Phone: +98 2186703270 \\ E-mail: akouchekian.m@ \\ iums.ac.ir
}


reotypical behavior, impaired verbal or nonverbal communication and delayed social interaction are the main symptoms [5].

mtDNA-related disorders such as Parkinson's disease (PD), Alzheimer's disease (AD), Huntington's disease (HD), mood disorder and schizophrenia are specially challenging because of the two different genes (nuclear DNA and mtDNA) involved in the pathogenesis [6]. These types of disorders can occur due to tRNA point mutations or deletions of mtDNA. The cells have thousands of mtDNA molecules. Mutations in the mtDNA result in heteroplasmy (mixture of wild-type and mutant mtDNA). By dividing heteroplasmic cells, these two types of mtDNA randomly spread between cells. Finally, diseases that occur due to defects in mtDNA are inherited from the mother to the children $[1,7]$.

The prevalence of autism in the USA is estimated to be 1 in 110 individuals. In Iran, the prevalence of autism in 5-year-old children with mitochondrial diseases is 6.26 in 10,000 . This is less than one percent of all autistic patients. Also studies of mtDNA show that humans originated in Africa $[8,9]$. In mammals, the mitochondrion is the only organelle with its own genome. In the mitochondria, the electron transport chain (ETC) is coded by mtDNA and nDNA. The mtDNA is 16.5 $\mathrm{kb}$ and there are 10s-1000s of copies of it in each cell. It has 37 genes that code for 13 subunits of complexes I, III, IV, and V. The remaining subunits are encoded by the nuclear genome $[7,10]$.

The electron transport chain (ETC) has five complexes among which ATPase $6 / 8$ is a part of the complex $V$ ATP synthase. In addition to these genes, there are 2 rRNA and 22 tRNA genes which are necessary for the synthesis of polypeptides. As a result, producing mitochondrial energy would definitely be affected by any mutation in the coding of mtDNA. Genetic variation in the mtDNA is a probable cause of autism. The mtDNA is abundant in the brain. It produces energy and is essential for the brain's function $[4,7,10]$.

There are few biological markers for diagnosis of autism. That's why a clinical diagnosis is solely based on behavioral observation. Up to now, treating patients with autism is done by using risperidone and aripiprazole, the only drugs that are approved by the FDA. Both of these drugs are atypical antipsychotics which are used to treat irritability, hyperactivity and aggression [3].
ATPase 6/8 genes and also the relationship between autism and $t R N A^{\text {Leu }}$ and $t R N A^{\text {Lys }}$ have been investigated in this study [5]. Because of the importance of this disease and increasing prevalence of it, the main objective of this study is to identify variants of ATPase 6/8 that play a role in producing energy and variants which occur in tRNA as potential risk factors.

\section{Material and methods}

\section{Subjects and samples}

We selected all children with autistic behaviors (15-60 CARS Score) without attention to presence or absence of similar behaviors in their relatives and assessed their blood (with complete consent) to detect mtDNA gene variants. We analyzed patients with a mean age of 3-5 years who in total comprised 6 girls and 25 boys.

\section{DNA extraction and PCR amplification}

The DNA extraction process was done by a GeNet Bio DNA extraction kit, and the regions of interest were amplified using independent PCR runs. PCR amplification was carried out in a final volume of $25 \mu \mathrm{l}$ containing 200-300 ng of total DNA and 12.5ul CinaGen PCR Master Kit Cat. No. PR8251C (CinaGen, Tehran, Iran) and 10 pmol of each primer (Table I). After initial denaturation for $5 \mathrm{~min}$ at $95^{\circ} \mathrm{C}, 38$ cycles of amplification were performed as follows: $55 \mathrm{~s}$ at $95^{\circ} \mathrm{C}, 50 \mathrm{~s}$ at $55^{\circ} \mathrm{C}$ at $60^{\circ} \mathrm{C}$ and $55 \mathrm{~s}$ at $72^{\circ} \mathrm{C}$ followed by $72^{\circ} \mathrm{C}$ for $10 \mathrm{~min}$. PCR products were checked for yield and purity on agarose gels (Figure 1).

\section{DNA sequencing}

Sequence analysis of PCR products was done after purification of PCR products (PCR product purification kit, Roche). Both strands were sequenced by the Big Dye Termination system in a directly determined automated sequencing on an $A B I 3700$ capillary sequencer machine using both primers (Macrogene, Seoul, Korea). Sequencing results were analyzed using bioinformatics' tools, Sequencher Software 5.

\section{Results}

In this study, 31 samples were examined of which 14 unique variants were detected in ATPase6/8

Table I. Primer sequences of study areas

\begin{tabular}{|c|c|c|c|c|}
\hline mtDNA genes & $\begin{array}{c}\text { Primer sequence } \mathrm{F} \\
3^{\prime} \rightarrow 5^{\prime}\end{array}$ & $\begin{array}{c}\text { Primer sequence R } \\
3^{\prime} \rightarrow 5^{\prime}\end{array}$ & Size [bp] & $\mathrm{T}_{\mathrm{m}}\left[{ }^{\circ} \mathrm{C}\right]$ \\
\hline tRNA Lys, ATPase 6 and 8 & CTACGGTCAATGCTCTGAAA & TACTATATGATAGGCATGTGA & 1078 & 55 \\
\hline tRNA leu & СTCAACTTAGTATTATACCC & GATGGTGAGAGCTAAGGTCG & 363 & 60 \\
\hline
\end{tabular}


and tRNA. All these variants were homoplasmic. The most frequent variant (58.97\%) is related to ATP6 with amino acid change $T \rightarrow A$. Overall, ATP6 has the most amino acid replacements, following ATP8 and tRNA ${ }^{\text {Lys }}$ (2.63\%). Some of these variants were reported previously in certain diseases, such as prostate tumor, colonic crypts and thyroid tumor with ATP6 mutation. No variants were found related to RRNA $^{\text {Lue }}$. The only pathogenic variant was G9055A (Table II, Figure 2).

\section{Discussion}

Fourteen unique amino acid replacements are seen in ATPase 6/8. Four of them encompass nonsyn replacements which are seen in ATPase 6. One of them known as G9055A (CAAD > 20 and PolyPhen indicates probably damaging) was shown to be pathogenic according to PolyPhen and CADD scores (Figure 1). ATPase 8 includes synonym replacements. Variants that were found in ATPase 6 have been reported in some cancers previously. G9055A variant is known as a Parkinson disease protective factor [11]. Five percent of children with defects in mitochondria are experiencing autism [12]. As a result, abnormalities in mitochondrial components' function can be used as a biomarker in diagnosis of autism. Studies have shown that the activity of complex $V$ (ATPase 6/8) in brain is higher than in other tissues [13]. This means that variants in the energy-generating pathway may make mitochondria stop producing ATP in the brain [14]. Subsequently, deficiencies in the ener-

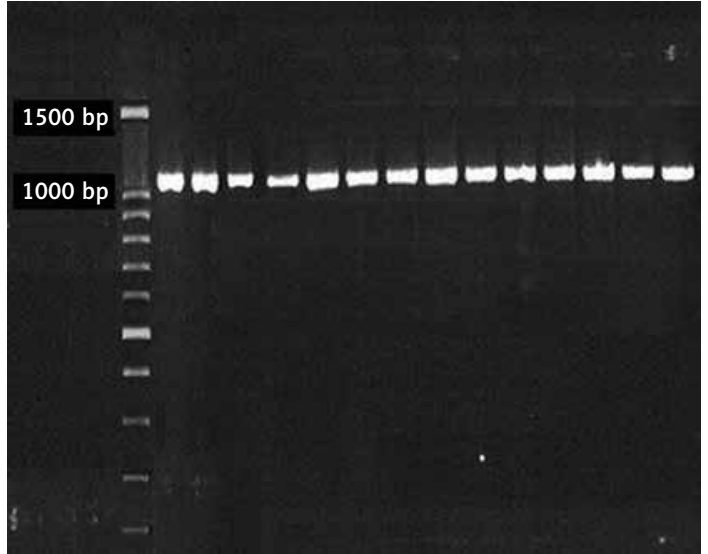

Figure 1. Gene product of tRNA leu/lys and ATPase 6 and 8 . All products are $1078 \mathrm{bp}$

gy-generating pathway as brain neuron fuel might lead to some of the cognitive impairments associated with autism [15]. Polymorphism A8860G appeared as many as 23 times in 31 cases. This polymorphism in the study of Houshmand et al. [16] appeared in $36 / 40$ of the autism patients.

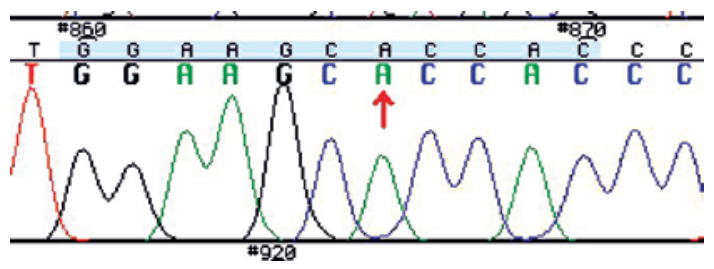

Figure 2. G9055A substitution in ATP6

Table II. Unique mutations in tRNA and ATPase6/8

\begin{tabular}{|c|c|c|c|c|c|c|c|}
\hline $\begin{array}{l}\text { Nucleotide } \\
\text { position }\end{array}$ & Locus & $\begin{array}{l}\text { Amino acid } \\
\text { change }\end{array}$ & Frequency (\%) & MutationTaster & $\begin{array}{l}\text { CADD } \\
\text { Score }\end{array}$ & PolyPhen & $\begin{array}{l}\text { Reported in } \\
\text { other disease }\end{array}$ \\
\hline A8860G & MT-ATP6 & $\mathrm{T} \rightarrow \mathrm{A}$ & $23(74)$ & Polymorphism & 6.12 & Benign & \\
\hline G8697A & MT-ATP6 & $M \rightarrow M$ & $2(6.44)$ & Disease_causing & 8.57 & - & Thyroid tumor \\
\hline G8994A & MT-ATP6 & $\mathrm{L} \rightarrow \mathrm{L}$ & $2(6.44)$ & Disease_causing & 9.35 & - & \\
\hline T8614C & MT-ATP6 & $\mathrm{L} \rightarrow \mathrm{L}$ & $1(3.22)$ & Polymorphism & 1.96 & - & \\
\hline G8557A & MT-ATP6 & $A \rightarrow P$ & $3(9.7)$ & Polymorphism & 8.62 & Benign & Colonic crypts \\
\hline G8392A & MT-ATP8 & $\mathrm{W} \rightarrow \mathrm{W}$ & $1(3.22)$ & Disease_causing & 11.6 & - & \\
\hline T8473C & MT-ATP8 & $\mathrm{P} \rightarrow \mathrm{P}$ & $1(3.22)$ & Polymorphism & 4.64 & - & \\
\hline C8434T & MT-ATP8 & $I \rightarrow I$ & $1(3.22)$ & Disease_causing & 12.92 & - & \\
\hline T8419C & MT-ATP8 & $\mathrm{L} \rightarrow \mathrm{L}$ & $1(3.22)$ & Disease_causing & 3.55 & - & \\
\hline T8937C & MT-ATP6 & $\mathrm{L} \rightarrow \mathrm{L}$ & $1(3.22)$ & Disease_causing & 4.58 & - & \\
\hline A8653G & MT-ATP6 & $\mathrm{P} \rightarrow \mathrm{V}$ & $1(3.22)$ & Polymorphism & 0.01 & Benign & Prostate tumor \\
\hline T8877C & MT-ATP6 & $\mathrm{F} \rightarrow \mathrm{F}$ & $1(3.22)$ & Disease_causing & 5.13 & - & \\
\hline G9055A & MT-ATP6 & $A \rightarrow T$ & $1(3.22)$ & Polymorphism & 22.6 & $\begin{array}{c}\text { Probably } \\
\text { damaging }\end{array}$ & $\begin{array}{l}\text { PD protective } \\
\text { factor }^{*}\end{array}$ \\
\hline A8331G & tRNA ${ }^{\text {lys }}$ & $A \rightarrow G$ & $1(2.56)$ & Polymorphism & 9.67 & - & \\
\hline
\end{tabular}

${ }^{\star}$ Parkinson disease protective factor. 
But it is necessary to take a closer look at the G9055A variant. In this variant, the amino acid alanine converts into threonine at position 9055 of ATP6 that shows pathogenesis. A to T substitutions induce accumulation of amyloid fibril because threonine prefers to form a $\beta$ sheet, as a necessary stage in amyloidogenic processes [17].

Previously the secretion of amyloid- $\beta$ precursor protein $\alpha$ form (SAPPa) in patients with mild-to-moderate autism was reported [18]. $\mathrm{N}$-truncated amyloid- $\beta$ causes the production of reactive oxygen species and lipid peroxidation which leads to mitochondrial injury, contributing to abnormal neuronal function [19]. Detecting specific mitochondrial variants which cause excessive expression of $\beta$-amyloid in autistic children is a great step in autism diagnosis and treatment. Previous studies showed that threonine amino acid plays an important role in amyloidosis [20]. There are at least 25 proteins forming the amyloid structure [21] which creates beta sheets. Making these sheets is an important step in amyloidosis. Theoretically valine is an amino acid that tends to create beta sheets [22]. In this study, a variant that led to the replacement of alanine with threonine was found. The main focus of our discussion is with regard to this variation.

Children with mild autism express $\beta$-amyloid at two or more times the levels of children without autism and this level exceeds four times in children with severe autism. This causes $\beta$-amyloid accumulation in the brain and leads to neurotoxicity and impaired transmission of nerve impulses $[23,24]$. Also, some studies have reported an association of autism with cancer [25]. In one study, it was reported that people with autism are more susceptible to prostate cancer in comparison with controls [26]. This suggests that individuals with autism have cancer risk due to the commonality of some genes in the cancer pathway [27]. Also dysfunction in ETC can increase the level of reactive oxygen species (ROS) and as a risk factor for cancer, promotes tumor progression [14, 28].

Another study reported G9055A as one of the most significant variants in the risk of breast cancer progression, pancreatic cancer and tubular and villous adenomas with the frequency of $10 \%$, $57 \%$ and $100 \%$ respectively. This variant is located in a protected area which has a destructive effect on the protein structure [29]. Overall G9055A variant has been reported in a few studies but merely as a simple report, without detailed assessment of its association with autism [1]. But, regarding previous related studies we find a correlation between this variant and amyloidosis and a correlation between amyloidosis and autism.

In conclusion, we conclude that defects in mitochondria affect multiple organs such as muscu- lar and gastrointestinal systems and the central nervous. These organs are affected in children with autism [30]. We can take steps for better recognition by mitochondrial genetic markers in these patients. In our study among the variations in autistic patients one case has an interesting association between G9055A and amyloidosis. We hope that through finding more biomarkers, autism diagnosis and treatment can be performed with more certainty.

\section{Acknowledgments}

This work was supported by grants from Cellular and molecular research center, Iran University of medical Sciences project number 25086.

\section{Conflict of interest}

The authors declare no conflict of interest.

\section{References}

1. Avdjieva-Tzavella D, Mihailova S, Lukanov C, et al. Mitochondrial DNA mutations in two Bulgarian children with autistic spectrum disorders. Balkan J Med Genet 2012; 15: 47-54.

2. Patowary A, Nesbitt R, Archer M, Bernier R, Brkanac Z. Next generation sequencing mitochondrial DNA analysis in autism spectrum disorder. Autism Res 2017; 10: 1338-43.

3. Penagarikano O. New therapeutic options for autism spectrum disorder: experimental evidences. Exp Neurobiol 2015; 24: 301-11.

4. Tang G, Gutierrez Rios P, Kuo SH, et al. Mitochondrial abnormalities in temporal lobe of autistic brain. Neurobiol Dis 2013; 54: 349-61.

5. Piryaei F, Houshmand M, Aryani O, Dadgar S, Soheili ZS. Investigation of the mitochondrial ATPase 6/8 and tRNA (Lys) genes mutations in autism. Cell J 2012; 14: 98-101.

6. Craven L, Alston CL, Taylor RW, Turnbull DM. Recent advances in mitochondrial disease. Annu Rev Genomics Hum Genet 2017; 18: 257-75.

7. Wei W, Keogh MJ, Wilson I, et al. Mitochondrial DNA point mutations and relative copy number in 1363 disease and control human brains. Acta Neuropathol Commun 2017; 5: 13.

8. Gonder MK, Mortensen HM, Reed FA, de Sousa A, Tishkoff SA. Whole-mtDNA genome sequence analysis of ancient African lineages. Mol Biol Evol 2007; 24: 757-68.

9. Samadi SA, McConkey R. Autism in developing countries: lessons from Iran. Autism Res Treatment 2011; 2011: 145359.

10. Rosti RO, Sadek AA, Vaux KK, Gleeson JG. The genetic landscape of autism spectrum disorders. Develop Med Child Neurol 2014; 56: 12-8.

11. Van Der Walt JM, Nicodemus KK, Martin ER, et al. Mitochondrial polymorphisms significantly reduce the risk of Parkinson disease. Am J Human Genet 2003; 72: 804-11.

12. Anitha A, Nakamura K, Thanseem I, et al. Brain region-specific altered expression and association of mitochondria-related genes in autism. Mol Autism 2012; 3: 12.

13. Frye RE, Rose S, Slattery J, MacFabe DF. Gastrointestinal dysfunction in autism spectrum disorder: the role of the 
mitochondria and the enteric microbiome. Microb Ecol Health Dis 2015; 26: 27458.

14. Siddiqui MF, Elwell C, Johnson MH. Mitochondrial dysfunction in autism spectrum disorders. Autism Open Access 2016; 6: 1000190

15. Napoli E, Wong S, Hertz-Picciotto I, Giulivi C. Deficits in bioenergetics and impaired immune response in granulocytes from children with autism. Pediatrics 2014; 133 : e1405-10.

16. Houshmand M, Mousavizadeh K, Askari M, Nikpour AR, Mazidi M, Tavafjadid M. Association of mtDNA mutation with autism in Iranian patients. Int J Pediatr 2013; 1: 39-43.

17. Podoly E, Hanin G, Soreq H. Alanine-to-threonine substitutions and amyloid diseases: butyrylcholinesterase as a case study. Chem Biol Interact 2010; 187: 64-71.

18. Frackowiak J, Mazur-Kolecka B, Schanen NC, Brown WT, Wegiel J. The link between intraneuronal N-truncated amyloid-beta peptide and oxidatively modified lipids in idiopathic autism and dup (15q11. 2-q13)/autism. Acta Neuropathol Commun 2013; 1: 61.

19. Ray B, Long JM, Sokol DK, Lahiri DK. Increased secreted amyloid precursor protein-alpha (sAPPalpha) in severe autism: proposal of a specific, anabolic pathway and putative biomarker. PLoS One 2011; 6: e20405.

20. Podoly E, Hanin G, Soreq H. Alanine-to-threonine substitutions and amyloid diseases: butyrylcholinesterase as a case study. Chem Biol Interact 2010; 187: 64 Y71.

21. Spillantini MG, Goedert M, Jakes R, Klug A. alpha-Synuclein in filamentous inclusions of Lewy bodies from Parkinson's disease and dementia with lewy bodies. Proc Natl Acad Sci USA 1990; 87: 3947-51.

22. Chou PY, Fasman GD. Conformational parameters for amino acids in helical, beta sheet, and random coil regions calculated from proteins. Biochemistry 1974; 13: 211-22.

23. Sanders KM. Amyloid precursor protein processing in autism and Alzheimer's disease and the potential therapeutic use of trehalose. ND dissertation, College of Naturopathic Medicine, Univ. of Bridgeport, Bridgeport, CT, 2013.

24. Sokol DK, Chen D, Farlow MR, et al. High levels of Alzheimer beta-amyloid precursor protein (APP) in children with severely autistic behavior and aggression. J Child Neurol 2006; 21: 444-9.

25. Crespi B. Autism and cancer risk. Autism Res 2011; 4: 302-10.

26. Ingudomnukul E, Baron-Cohen S, Wheelwright S, Knickmeyer R. Elevated rates of testosterone-related disorders in women with autism spectrum conditions. Horm Behav 2007; 51: 597-604.

27. Crawley JN, Heyer WD, LaSalle JM. Autism and cancer share risk genes, pathways, and drug targets. Trends Genet 2016; 32: 139-46.

28. Liou GY, Storz P. Reactive oxygen species in cancer. Free Rad Res 2010; 44: 479-96.

29. Ghaffarpour M, Mahdian R, Fereidooni F, Kamalidehghan B, Moazami N, Houshmand M. The mitochondrial ATPase6 gene is more susceptible to mutation than the ATPase8 gene in breast cancer patients. Cancer Cell Int 2014; 14: 21.

30. Frye RE, Rossignol DA. Mitochondrial dysfunction can connect the diverse medical symptoms associated with autism spectrum disorders. Pediatr Res 2011; 69: 41R-7R. 